\title{
Macular and Retinal Nerve Fibre Layer Thickness in Pregnant Women with Gestational Diabetes Mellitus
}

This article was published in the following Dove Press journal: Clinical Ophthalmology

\author{
Amir Tengku-Fatishah $\mathbb{D}^{1,2}$ \\ Nik Lah Nik-Ahmad- \\ Zuky $\mathbb{( D D}^{3,4}$ \\ Ismail Shatriah $\mathbb{D}^{1,2}$
}

'Department of Ophthalmology, School of Medical Sciences, Universiti Sains Malaysia, Kubang Kerian 16150, Kelantan, Malaysia; ${ }^{2}$ Ophthalmology Clinic, Hospital Universiti Sains Malaysia, Kubang Kerian, Kelantan, 16150, Malaysia; ${ }^{3}$ Department of Obstetric and Gynecology, School of Medical Sciences, Universiti Sains Malaysia, Kubang Kerian, Kelantan, 16150, Malaysia; ${ }^{4}$ Obstetrics and Gynecology Clinic, Hospital Universiti Sains Malaysia, Kubang Kerian,Kelantan, 16150, Malaysia

Correspondence: Ismail Shatriah

Department of Ophthalmology, School of Medical Sciences, Universiti Sains

Malaysia, Kubang Kerian 16150, Kelantan, Malaysia

Email shatriah@usm.my
Background: The information about macular and retinal nerve fibre layer (RNFL) thickness in women with gestational diabetes mellitus (GDM) is scarce. GDM is a risk factor for development of type 2 diabetes mellitus.

Purpose: The purpose of this study was to evaluate mean macular and RNFL thickness in pregnant women with GDM in a teaching institution in Malaysia. We also analyzed the association of age, HbAlc level, duration of GDM, type of treatment, family history, previous history of GDM and spherical equivalent with the macular and RNFL thickness.

Patients and Methods: This was a prospective and cross-sectional study involving 78 pregnant women with GDM, 72 healthy pregnant and 70 healthy non-pregnant women. The study was conducted in Hospital Universiti Sains Malaysia from 2016 to 2018. Macular and RNFL thickness were measured during the third trimester using spectral-domain optical coherence tomography. Age, HbA1c level, duration of GDM, type of treatment, family history, previous history of GDM and spherical equivalent were analysed.

Results: The mean macular thickness was 236.08 (16.44) $\mu \mathrm{m}, 237.26$ (22.42) $\mu \mathrm{m}$ and 240.66 (20.95) $\mu \mathrm{m}$ for GDM, healthy pregnant, and healthy non-pregnant women. The mean RNFL thickness was 97.27 (9.14) $\mu \mathrm{m}, 99.83$ (12.44) $\mu \mathrm{m}$ and 97.97 (10.07) $\mu \mathrm{m}$ for GDM, healthy pregnant, and healthy non-pregnant women. There was no significant difference in the mean macular and RNFL thickness in pregnant women with GDM when compared to the control groups $(\mathrm{p}>0.05)$. Age, HbA1c, duration of diabetes, treatment received, history of GDM and spherical equivalent did not show significant association with mean macular and retinal thickness $(\mathrm{p}>0.05)$.

Conclusion: Pregnant women with GDM have similar thickness of the macular and RNFL with the healthy pregnant and healthy non-pregnant women. Age, HbAlc, duration of diabetes, treatment received, history of GDM and spherical equivalent showed no significant association with mean macular and retinal thickness in pregnant women with GDM.

Keywords: gestational diabetes mellitus, pregnant women, healthy women, macular thickness, retinal nerve fibre layer thickness

\section{Introduction}

Gestational diabetes mellitus (GDM) is a glucose intolerance state which is induced by pregnancy, and the condition may resolve or persist after the pregnancy period. ${ }^{1,2}$ The prevalence of GDM ranges from $2 \%$ to $9 \%$, and it is considered a growing problem worldwide. $^{3}$ The prevalence of GDM in Malaysia was reported to be $8.83 \%{ }^{4}$

Changes in central cornea thickness, intraocular pressure, retinal microvasculature, and alteration in retinal nerve fibre layer and choroidal thickness had been 
reported in pregnant women with GDM. ${ }^{5-9}$ There is a limited data about retinal changes in these patients. Pregnant women with diabetes have shown higher retina capillary blood flow which can be persistent up to threemonths postpartum. ${ }^{10}$

Women with GDM have sevenfold increased relative risk to progress to type 2 diabetes mellitus. ${ }^{11-13}$ They are usually asymptomatic until they develop macular edema or proliferative diabetic retinopathy. Thus, it is important to examine the eye during early stage of the disease. In this study, we aimed to compare mean macular and retinal nerve fibre layer (RNFL) thickness between pregnant women with GDM and healthy pregnant women in their third trimesters. We also studied the association of the identified variables with the mean macular and RNFL thickness in the studied group.

\section{Patients and Methods}

A prospective cross-sectional study was performed in Hospital Universiti Sains Malaysia from December 2016 to June 2018. We included 220 eyes from 78 pregnant women with GDM (78 eyes), 72 healthy pregnant women (72 eyes), and 70 healthy non-pregnant women (70 eyes) in this study. Approval for the study was obtained from the Research and Ethics Committee, School of Medical Sciences, Universiti Sains Malaysia, and consistent with the tenets of the Declaration of Helsinki.

All participants were 20-45 years old. Inclusion criteria for pregnant women with GDM included confirmed diagnosis of GDM based on the following:

(i) 75-gram oral glucose tolerance test (OGTT) with the cut-off value for fasting glucose concentration at $\geq 5.1 \mathrm{mmol} / 1$,

(ii) and/or the 2-hour postprandial level at $\geq 7.8 \mathrm{mmol} / 1 .^{11}$

Inclusion criteria for healthy pregnant women and nonpregnant women included absence of pre-existing medical illness.

Exclusion criteria for all three groups included:

(i) the presence of concurrent medical and ophthalmic illness, consuming medications (except for iron and folic acid tablets)

(ii) and history of ocular trauma or any intraocular surgery including refractive surgery

(iii) refractive error beyond \pm 4.0 diopters

(iv) axial length exceeding the $22-25 \mathrm{~mm}$ range (v) best-corrected visual acuity poorer than 6/12 (20/40).

Pregnant women with GDM and healthy pregnant women with singleton pregnancy and gestational weeks at third trimester, who attended the Obstetrics or Ophthalmology Clinics were recruited in the study. Meanwhile, the nonpregnant subjects were recruited through voluntary participation from our institution's female staff of reproductive age.

Written informed consent was obtained from all subjects. Demographic data included age, duration of GDM, type of treatment, family history and previous history of GDM were recorded. A thorough ocular examination was performed, including best-corrected visual acuity, refraction, intraocular pressure documentation, anterior segment, and funduscopy examinations. The previous level of HbA1c within three months was also recorded.

Macular and RNFL thickness was measured with spectral-domain optical coherence tomography (OCT), Cirrus HD OCT (Carl Zeiss Meditec, USA). Mean macular image was captured based on the macular map protocol, using Early Treatment Diabetic Retinopathy Study circles of $1 \mathrm{~mm}$ (central fovea), $3 \mathrm{~mm}$ (inner macula), and $6 \mathrm{~mm}$ (outer macula). There were nine subfield regions in the circles; namely, fovea central subfield, superior inner, inferior inner, nasal inner, temporal inner, superior outer, inferior outer, nasal outer, and temporal outer of macula. The peripapillary RNFL region was divided into four quadrants: superior, inferior, nasal, and temporal. Analysis was performed on the right eye. Images with signal strength $>5$ were analyzed. The thickness measurement was only taken once during the third trimester.

Statistical Package for Social Science (SPSS) version 24 was used. The mean macular and RNFL thickness were analyzed using descriptive analysis. A one-way ANOVA test was used to compare the mean macular and RNFL thickness in the three groups. The association between the mean macular and RNFL thickness with age, HbA1c level, duration, type of treatment, family history, previous history of GDM, and spherical equivalent tested using a simple linear regression and multiple linear regression test. A p-value of less than $0.05(\mathrm{p}<0.05)$ was taken as statistically significant.

\section{Results}

Demographic and baseline characteristics of the subjects are shown in Table 1. All subjects presented with good vision, with at least $6 / 9(20 / 30)$ or better. None of the subjects presented with clinical diabetic retinopathy or macular edema during assessment. 
Table I Demographic and Baseline Characteristics

\begin{tabular}{|c|c|c|c|c|}
\hline Parameters & $\begin{array}{l}\text { Pregnant } \\
\text { with } \\
\text { GDM }\end{array}$ & $\begin{array}{l}\text { Healthy } \\
\text { Pregnant }\end{array}$ & $\begin{array}{l}\text { Healthy } \\
\text { Non- } \\
\text { Pregnant }\end{array}$ & p-value \\
\hline Age (years), mean (SD) & $33.2(5.7)$ & $31.6(4.9)$ & $32.5(8.3)$ & $0.549^{\mathrm{a}}$ \\
\hline Gravida, mean (SD) & $3.1(1.9)$ & $2.7(1.8)$ & NA & $0.176^{\mathrm{c}}$ \\
\hline Parity, mean (SD) & $1.9(1.5)$ & $1.7(1.7)$ & $1.3(1.7)$ & $0.117^{\mathrm{a}}$ \\
\hline $\begin{array}{l}\text { Gestation (weeks), mean } \\
\text { (SD) }\end{array}$ & $31.3(4.7)$ & $28.4(4.3)$ & NA & $0.549^{c}$ \\
\hline Family history of DM, $\mathrm{n}(\%)$ & $52(43.0)$ & $39(32.2)$ & $30(24.8)$ & $0.014^{\mathrm{b}}$ \\
\hline History of GDM, n (\%) & $24(30.8)$ & NA & NA & NA \\
\hline HbAlc (\%), mean (SD) & $5.6(0.56)$ & NA & NA & NA \\
\hline $\mathrm{SBP}(\mathrm{mmHg})$, mean $(\mathrm{SD})$ & $\begin{array}{l}116.0 \\
(10.26)\end{array}$ & $\begin{array}{l}116.4 \\
(10.5 I)\end{array}$ & $\begin{array}{l}120.7 \\
(8.44)\end{array}$ & $0.007^{\mathrm{a}}$ \\
\hline $\mathrm{DBP}(\mathrm{mmHg})$, mean (SD) & $\begin{array}{l}73.06 \\
(11.49)\end{array}$ & $\begin{array}{l}72.2 \\
(6.97)\end{array}$ & $\begin{array}{l}72.4 \\
(7.13)\end{array}$ & $0.819^{\mathrm{a}}$ \\
\hline $\begin{array}{l}\text { Duration of GDM } \\
\text { (weeks), mean (SD) }\end{array}$ & I3.I (6.40) & NA & NA & NA \\
\hline $\begin{array}{l}\text { Type of Treatment, } n(\%) \\
\text { Diet } \\
\text { Insulin }\end{array}$ & $\begin{array}{l}49(62.8) \\
29(37.2)\end{array}$ & NA & NA & NA \\
\hline $\begin{array}{l}\text { Spherical equivalent } \\
\text { (diopters), mean (SD) } \\
\text { Axial length (mm), mean } \\
\text { (SD) }\end{array}$ & $\begin{array}{l}-1.20 \\
(1.14) \\
23.32 \\
(0.72)\end{array}$ & $\begin{array}{l}-1.44 \\
(1.28) \\
23.67 \\
(0.88)\end{array}$ & $\begin{array}{l}-1.15 \\
(1.21) \\
23.60 \\
(0.83)\end{array}$ & $\begin{array}{l}0.315^{\mathrm{a}} \\
0.023^{\mathrm{a}}\end{array}$ \\
\hline
\end{tabular}

Notes: ane-way ANOVA, 'Pearson chi-square test, 'Fisher's exact test, $p<0.05$ is significant.

Abbreviations: GDM, gestational diabetes mellitus; DM, diabetes mellitus; HbAlc, glycated hemoglobin; SBP, systolic blood pressure; DBP, diastolic blood pressure; SD, standard deviation; NA, not applicable.

Table 2 presents the comparison of mean macular thickness between the studied groups. Table 3 shows the comparison of mean RNFL thickness in GDM, healthy pregnant, and healthy non-pregnant women. There was no statistically significant difference in mean macular and RNFL thickness in pregnant women with GDM compared to healthy pregnant and healthy non-pregnant women $(\mathrm{p}>0.05)$.

Age, HbAlc, duration of diabetes, treatment received, history of GDM and spherical equivalent did not show any significant association with mean macular and retinal thickness in pregnant women with GDM ( $>0.05)$. These are summarized in Table 4.

\section{Discussion}

Pregnancy commonly accelerates pre-existing retinal disease, especially diabetic retinopathy in pre-GDM. ${ }^{14}$ The possible causes for exacerbation of diabetic retinopathy during pregnancy includes hematologic, hormonal, metabolic, cardiovascular and immunologic changes. ${ }^{10}$ Other studies have reported that the neurodegenerative changes occurred before diabetic retinopathy took place in subjects with type 2 DM. ${ }^{15-17}$

We found that pregnant women with GDM had similar mean macular thickness compared to healthy pregnant and healthy non-pregnant women. Table 5 summarizes the published study on pregnant women with GDM, healthy pregnant women, and non-pregnant women, and including our study. Our data showed a similar outcome with Acmaz et al who measured macular thickness in 36 pregnant women with GDM, 24 healthy pregnant women, and 38 non-pregnant women in the Turkish population. ${ }^{7}$ They reported that the difference in mean macular thickness between pregnant women with GDM and healthy pregnant women was non-significant $(p>0.05){ }^{7}$

Our result showed no significant difference in the mean RNFL thickness based on each quadrant in the studied groups $(p>0.05)$. In contrast, Sasikumar et al reported

Table 2 Comparison of Mean Macular Thickness in Each Group

\begin{tabular}{|l|l|l|l|l|}
\hline \multirow{2}{*}{ Parameter } & Pregnant with GDM & Healthy Pregnant Women & Healthy Non-Pregnant Women & *p-value \\
\cline { 2 - 5 } & & Mean (SD) & & 0.639 \\
\hline Average & $273.83(14.42)$ & $275.10(15.27)$ & $276.03(12.25)$ & 0.360 \\
Foveal & $236.08(16.44)$ & $237.26(22.42)$ & $240.66(20.95)$ & 0.500 \\
Superior inner & $313.77(15.15)$ & $3 I 1.31(19.69)$ & $314.49(15.72)$ & $0.79 \mid$ \\
Inferior inner & $308.88(16.10)$ & $309.07(16.88)$ & $310.56(15.12)$ & 0.492 \\
Temporal inner & $299.54(15.26)$ & $298.29(17.04)$ & $301.36(13.66)$ & 0.716 \\
Nasal inner & $313.42(18.30)$ & $313.06(18.30)$ & $315.17(15.28)$ & 0.864 \\
Superior outer & $277.87(13.87)$ & $276.89(14.67)$ & $278.10(14.23)$ & 0.212 \\
Inferior outer & $264.87(14.87)$ & $269.44(18.97)$ & $266.27(14.22)$ & 0.818 \\
Temporal outer & $255.59(13.87)$ & $255.74(13.22)$ & $256.89(13.15)$ & $>0.950$ \\
Nasal outer & $295.2 I(14.95)$ & $295.17(17.44)$ & $295.03(15.28)$ & \\
\hline
\end{tabular}

Notes: *One way ANOVA, $\mathrm{p}<0.05$ is significant.

Abbreviations: GDM, gestational diabetes mellitus; SD, standard deviation. 
Table 3 Comparison of Mean RNFL Thickness in Each Group

\begin{tabular}{|l|l|l|l|l|}
\hline \multirow{2}{*}{ Parameter } & Pregnant with GDM & Healthy Pregnant & Healthy Non-Pregnant \\
\cline { 2 - 5 } & & Mean (SD) & & \\
\hline Average & $97.27(9.14)$ & $99.83(12.44)$ & $97.97(10.07)$ & 0.327 \\
Superior & $120.81(15.85)$ & $121.80(22.50)$ & $120.70(16.99)$ & 0.927 \\
Inferior & $128.33(15.84)$ & $133.54(21.09)$ & $131.74(18.23)$ & 0.217 \\
Temporal & $70.05(12.40)$ & $70.00(I I .82)$ & $70.34(11.82)$ & 0.852 \\
Nasal & $70.63(9.7 I)$ & $73.06(16.4 I)$ & $68.43(11.5 I)$ & 0.102 \\
\hline
\end{tabular}

Notes: *One way ANOVA, $\mathrm{p}<0.05$ is significant.

Abbreviations: RNFL, retinal nerve fibre layer; GDM, gestational diabetes mellitus; SD, standard deviation.

Table 4 Association of Mean Macular and RNFL Thickness in GDM with Possible Confounding Factors

\begin{tabular}{|c|c|c|c|c|}
\hline \multirow[t]{2}{*}{ Variables } & b $(95 \% \mathrm{Cl})$ & p-value & b $(95 \% \mathrm{Cl})$ & p-value \\
\hline & \multicolumn{2}{|c|}{ Simple Linear Regression } & \multicolumn{2}{|c|}{ Multiple Linear Regression } \\
\hline \multicolumn{5}{|l|}{ Macular Thickness } \\
\hline $\begin{array}{l}\text { Age, per year } \\
\text { HbAlc } \\
\text { Duration }\end{array}$ & $\begin{array}{l}0.46(-0.62,0.7 \mathrm{I}) \\
-0.07(-6.84,6.70) \\
-0.25(-0.84,0.33)\end{array}$ & $\begin{array}{l}0.890 \\
0.983 \\
0.390\end{array}$ & & \\
\hline $\begin{array}{l}\text { Treatment } \\
\text { Diet } \\
\text { Insulin }\end{array}$ & $\begin{array}{l}\text { I } \\
2.02(-5.69,9.73)\end{array}$ & 0.604 & & \\
\hline $\begin{array}{l}\text { Family History of DN } \\
\text { Yes } \\
\text { No }\end{array}$ & $\begin{array}{l}\text { I } \\
0.53(-4.83,5.88)\end{array}$ & 0.847 & & \\
\hline $\begin{array}{l}\text { History of GDM } \\
\text { Yes } \\
\text { No }\end{array}$ & I $1.97(-0.80,4.75)$ & 0.163 & & \\
\hline Spherical equivalent & $1.63(0.09,3.18)$ & 0.038 & $0.497(-1.38,2.38)$ & 0.603 \\
\hline $\begin{array}{l}\text { RNFL Thickness } \\
\text { Age, per year } \\
\text { HbAlc } \\
\text { Duration }\end{array}$ & $\begin{array}{l}-0.23(-0.45,-0.01) \\
-1.92(-5.66,1.83) \\
-0.20(-0.53,0.13)\end{array}$ & $\begin{array}{l}0.052 \\
0.310 \\
0.225\end{array}$ & & \\
\hline $\begin{array}{l}\text { Treatment } \\
\text { Diet } \\
\text { Insulin }\end{array}$ & I $1.26(-3.08,5.59)$ & 0.566 & & \\
\hline $\begin{array}{l}\text { Family History of DN } \\
\text { Yes } \\
\text { No }\end{array}$ & $\begin{array}{l}\text { I } \\
0.29(-2.57,3.14)\end{array}$ & 0.844 & & \\
\hline $\begin{array}{l}\text { History of GDM } \\
\text { Yes } \\
\text { No }\end{array}$ & $\begin{array}{l}\text { I } \\
\text { I.68 }(-0.38,3.74)\end{array}$ & 0.109 & & \\
\hline Spherical equivalent & $1.32(0.16,2.47)$ & 0.062 & & \\
\hline
\end{tabular}

Note: $p<0.05$ is significant.

Abbreviations: HbAlc, glycated hemoglobin; DM, diabetes mellitus; GDM, gestational diabetes mellitus; RNFL, retinal nerve fibre layer; b, regression coefficient, $\mathrm{Cl}$, confidence interval. 
Table 5 Comparison of Mean Macular and RNFL Thickness During Third Trimester in GDM, Healthy Pregnant Women and Healthy Non-Pregnant Women in Previously Published Studies

\begin{tabular}{|c|c|c|c|c|c|c|c|c|}
\hline \multirow{3}{*}{$\begin{array}{l}\text { Country } \\
\text { Population } \\
\text { (Number) }\end{array}$} & \multicolumn{3}{|c|}{ Present Study, 2020} & \multicolumn{3}{|c|}{ Acmaz et al, $2015^{7}$} & \multicolumn{2}{|c|}{$\begin{array}{l}\text { Sasikumar et al, } \\
2018^{8}\end{array}$} \\
\hline & \multicolumn{3}{|l|}{ Malaysia } & \multicolumn{3}{|l|}{ Turkey } & \multicolumn{2}{|l|}{ India } \\
\hline & $\begin{array}{l}\text { GDM } \\
\text { Women }\end{array}$ & $\begin{array}{l}\text { Pregnant } \\
\text { Women }\end{array}$ & $\begin{array}{l}\text { Non- } \\
\text { Pregnant } \\
\text { Women }\end{array}$ & $\begin{array}{l}\text { GDM } \\
\text { Women }\end{array}$ & $\begin{array}{l}\text { Pregnant } \\
\text { Women }\end{array}$ & $\begin{array}{l}\text { Non- } \\
\text { Pregnant } \\
\text { Women }\end{array}$ & $\begin{array}{l}\text { GDM } \\
\text { Women }\end{array}$ & $\begin{array}{l}\text { Pregnant } \\
\text { Women }\end{array}$ \\
\hline Number of patients & 78 & 72 & 70 & 72 & 48 & 76 & 176 & 188 \\
\hline Gestational weeks & \multicolumn{2}{|c|}{ 28-38 weeks } & NA & NA & $\begin{array}{l}24-40 \\
\text { weeks }\end{array}$ & NA & \multicolumn{2}{|c|}{ 32-34 weeks } \\
\hline $\begin{array}{l}\text { Age (years), mean } \\
\text { (SD) }\end{array}$ & $\begin{array}{l}33.18 \\
(5.68)\end{array}$ & $31.57(4.90)$ & $32.47(8.25)$ & $\begin{array}{l}32.51 \\
(4.88)\end{array}$ & $27.72(5.12)$ & $31.87(7.76)$ & 28 (NA) & 28 (NA) \\
\hline $\begin{array}{l}\text { Macular thickness } \\
(\mu \mathrm{m}), \text { mean }(\mathrm{SD})\end{array}$ & $\begin{array}{l}236.08 \\
(16.44)\end{array}$ & $\begin{array}{l}237.26 \\
(22.42)\end{array}$ & 240.66 (20.95) & $\begin{array}{l}252.53 \\
(18.70)\end{array}$ & $\begin{array}{l}255.58 \\
(17.54)\end{array}$ & 265.09 (2I.67) & NA & NA \\
\hline $\begin{array}{l}\text { RNFL thickness, }(\mu \mathrm{m}) \text {, } \\
\text { mean }(\mathrm{SD})\end{array}$ & $\begin{array}{l}97.27 \\
(9.14)\end{array}$ & $\begin{array}{l}99.83 \\
(12.44)\end{array}$ & 97.97 (10.07) & $\begin{array}{l}101.93 \\
(8.72)\end{array}$ & $\begin{array}{l}104.45 \\
(10.06)\end{array}$ & 99.59 (12.02) & $\begin{array}{l}91.16 \\
(13.25)\end{array}$ & $\begin{array}{l}100.75 \\
(41.55)\end{array}$ \\
\hline Instrument & \multicolumn{3}{|c|}{ Cirrus HD-OCT } & \multicolumn{3}{|c|}{ Heidelberg Spectralis OCT } & \multicolumn{2}{|c|}{ Cirrus HD-OCT } \\
\hline
\end{tabular}

Abbreviations: RNFL, retinal nerve fibre layer; GDM, gestational diabetes mellitus; SD, standard deviation; OCT, optical coherence tomography; NA, not available.

that there was a significant difference in the average mean RNFL thickness and all quadrants ( $<<0.05)$, except for the temporal area $(\mathrm{p}=0.132)$ in pregnant women with GDM. They measured mean RNFL thickness in 176 pregnant women with GDM and 188 healthy pregnant women in India during their third trimester of pregnancy using the Cirrus HD OCT, ${ }^{8}$ which was similar to the OCT system used in our study. Acmaz et al also reported contrary results to ours. They demonstrated that the nasal part of the RNFL was thinner compared to other quadrants $(p<0.05)$, and suggested that the thinning of the nasal RNFL area is the earliest sign of neurodegenerative changes in GDM. ${ }^{7}$

The differences in our data could be due to early onset of the disease, good diabetic control and treatment compliance. The mean duration of GDM was 13.1 (6.40) weeks. The mean HbA1c was $5.6(0.56) \%$. $62.8 \%$ of our subjects were on dietary control, while, another $37.2 \%$ were commenced on insulin therapy. Meanwhile, both Sasikumar et al and Acmaz et al did not mention about their subjects' disease duration, glucose control and also treatment received in their reports. ${ }^{7,8}$

In addition, the discrepancies could also be due to the different spectral- domain OCT systems used. Our study obtained measurements with the Cirrus Spectralis HD OCT, while Acmaz et al used the Heidelberg Spectralis
OCT. It is interesting to note that these two spectralis OCT systems are different in several aspects, including in the mapping protocol, foveal central subfield area measurement, pixel resolutions, and data formatting. ${ }^{16}$ In their comparison of the two systems, Sander et al also concluded that the Heidelberg Spectralis OCT showed a thicker macular layer compared to the Cirrus, with a mean of $3.32 \mu \mathrm{m}$ in all quadrants $(\mathrm{p}<0.01){ }^{18}$

Kida et al have demonstrated that optic nerve head perfusion decreased in the glucose-intolerant group during the 75 -gram OGTT. ${ }^{19}$ They postulated that the accumulation of endothelin-1, which is the most potent vasoconstrictor peptide in the eye, occurs during the hyperglycemic state and further suppresses the ocular blood flow. ${ }^{19}$ Meanwhile, Yamagishi et al have found that the pigment epithelium-derived growth factor (PEDF) which has an anti-atherogenic property, is stimulated in a high glucose state. ${ }^{20}$ Therefore, both endothelin1 and PEDF levels suppress the vascular endothelial growth factors and further impair ocular perfusion, causing the thinning of RNFL in pregnant women with GDM. ${ }^{19,20}$ Both Acmaz et al and Sasikumar et al postulated that the thinning of the RNFL layer in GDM is due to excessive production of endothelin- 1 and PEDF. ${ }^{7,8}$

Neurodegenerative process began to occur 7.5 months after introduction of diabetes into their animal 
model. ${ }^{21}$ Barber et al reported that the retinal thinning involved $14 \%$ of the inner nuclear layer, $22 \%$ of the inner plexiform layer, and $10 \%$ of the diminished ganglion cells layer. ${ }^{21}$ We postulate that the transient glucose intolerance effect in our subjects was the reason for no significant difference being found in the mean macular and RNFL thickness in the GDM group. In addition, good treatment compliance, a low HbAlc level, and preexisting normal macular/retinal thickness possibly contributed to our study outcome.

The result of Sasikumar et $\mathrm{al}^{8}$ also agree with our finding, as the HbA1c level did not show a significant correlation with RNFL thickness in GDM. In contrast, the uncontrolled fasting blood glucose and 1-hour postOGTT levels were significantly associated with RNFL thinning in pregnant women with GDM. ${ }^{7}$ We had difficulty to recruit subjects with uncontrolled GDM because they have been monitored closely by the obstetricians. We recommend inclusion of pregnant women with GDM who have poor diabetic control and pregnant women with pregestational diabetes mellitus in future studies to give a more global picture. This may lead to the detection of significant changes in macular and RNFL thickness when compared with the GDM group.

\section{Conclusion}

The mean macular and RNFL thickness in pregnant women with GDM appears comparable to that in healthy pregnant women and healthy non-pregnant women. Age, HbA1c, duration of diabetes, treatment received, history of GDM and spherical equivalent did not have any association with mean macular and retinal thickness in pregnant women with GDM.

\section{Acknowledgments}

We would like to extend our gratitude to the staffs of the Ophthalmology and Obstetrics and Gynecology Clinics, Hospital Universiti Sains Malaysia, Malaysia, for their cooperation and support during data collection.

\section{Disclosure}

The authors report no conflict of interest in this work.

\section{References}

1. Chiefari E, Arcidiacono B, Foti D, Brunetti A. Gestational diabetes mellitus: an updated overview. J Endocrinol Invest. 2017;40:899-909. doi:10.1007/s40618-016-0607-5
2. American Diabetes Association. Diagnosis and classification of diabetes mellitus. Diabetes Care. 2014;37:S81-90. doi:10.2337/dc14S081

3. Correa P, Vargas FJ, Sen S, Illanes SE. Prediction of gestational diabetes in early pregnancy:targeting the long term complications. Gynecol Obstet Invest. 2014;77:145-149. doi:10.1159/000357616.

4. Jeganathan R, Karalasingam SD. 4th report of national obstetric registry. Ministry of Health, Malaysia, 2013-2015. Available from: http://www.acrm.org.my/nor/reports.php.

5. Santiagu F, Bakhtiari A, Iqbal T, Khaliddin N, Lansingh VC, Subrayan V. Diabetes and pachymetry changes in pregnancy. Int Ophthalmol. 2018;38:2069-2076. doi:10.1007/s10792-017-0701-5.

6. Li LJ, Kramer M, Tapp RJ, et al. Gestational diabetes mellitus and retinal microvasculature. BMC Ophthalmol. 2017;17:4. doi:10.1186/ s12886-016-0398-7.

7. Acmaz G, Atas M, Gulhan A, et al. Assessment of macular peripapillary nerve fiber layer and choroidal thickness changes in pregnant women with gestational diabetes mellitus, healthy pregnant women, and healthy non-pregnant women. Med Sci Monit. 2015;21:1759-1764. doi:10.12 659/MSM.893221.

8. Sasikumar M, Kakknatt CVA, Mathai MT. RNFL variation in gestational diabetes mellitus: an optical coherence tomography based study. Indian J Clin Exp Ophthalmol. 2018;4:168-174. doi:10.18231/23951451.2018.0038.

9. Benfica CZ, Zanella T, Farias LB, Oppermann MLR, Canani LHS, Lavinsky D. Macular choroidal thickness in pregnant women with type 1 , type 2 and gestational diabetes mellitus measured by spectral-domain optical coherence tomography. Clin Ophthalmol. 2018;12:1259-1265. doi:10.2147/OPTH.S166620.

10. Loukovaara S, Immonen IR, Loukovaara MJ, Koistenen R, Kaaja RJ. Glycodelin: a novel serum anti-inflammatory marker in type 1 diabetic retinopathy during pregnancy. Acta Ophthalmol Scand. 2007;85:46-49. doi:10.1111/j.1600-0420.2006.00766.x

11. Zhu Y, Zhang C. Prevalence of gestational diabetes and risk of progression to type 2 diabetes: a global perspective. Curr Diab Rep. 2016;16:7. doi:10.1007/s11892-015-0699-x.

12. Sandsæter HL, Horn J, Rich-Edwards JW, Haugdahl HS. Preeclampsia, gestational diabetes and later risk of cardiovascular disease: women's experiences and motivation for lifestyle changes explored in focus group interviews. BMC Pregnancy Childbirth. 2019;19:448. doi:10.1186/s12884-019-2591-1.

13. Nguyen CL, Pham NM, Binns CW, Duong DV, Lee AH. Prevalence of gestational diabetes mellitus in Eastern and Southeastern Asia: a systematic review and meta-analysis. $J$ Diabetes Res. 2018;2018:6536974. doi:10.1155/2018/6536974.

14. Errera MH, Kohly RP, da Cruz L. Pregnancy-associated retinal diseases and their management. Surv Ophthalmol. 2013;58:127-142. doi:10.1016/j.survophthal.2012.08.001.

15. Van Dijk HW, Verbraak FD, Kok PH, et al. Early neurodegeneration in the retina of type 2 diabetic patients. Invest Ophthalmol Vis Sci. 2012;53:2715-2719. doi:10.1167/iovs.11-8997.

16. De Clerck EEB, Schouten JSAG, Berendschot TTJM, et al. Macular thinning in prediabetes or type 2 diabetes without diabetic retinopathy: the Maastricht Study. Acta Ophthalmol. 2018;96:174-182. doi:10.1111/aos.13570.

17. Jiang J, Liu Y, Chen Y, et al. Analysis of changes in retinal thickness in type 2 diabetes without diabetic retinopathy. $J$ Diabetes Res. 2018;2018:3082893. doi:10.1155/2018/3082893.

18. Sander B, Al-Abiji HA, Kofod M, Jørgensen TM. Do different spectral domain OCT hardwares measure the same? Comparison of retinal thickness using third-party software. Graefes Arch Clin Exp Ophthalmol. 2015;253:1915-1921. doi:10.1007/s00417-015-3075-2.

19. Kida T, Sugiyama T, Oku H, Harino S, Ikeda T. Plasma endothelin-1 levels depress optic nerve head circulation detected during the glucose tolerance test. Graefe's Arch Clin Exp Ophthalmol. 2007;245:1289-1293. doi:10.1007/s00417-006-0525-x 
20. Yamagishi S, Matsui T, Nakamura K. Atheroprotective properties of pigment epithelium-derived factor (PEDF) in cardiometabolic disorders. Curr Pharm Des. 2009;15:1027-1033. doi:10.2174/ 138161209787581940
21. Barber AJ, Gardner TW, Abcouwer SF. The significance of vascular and neural apoptosis to the pathology of diabetic retinopathy. Invest Ophthalmol Vis Sci. 2011;52:1156-1163. doi:10.1167/iovs.10-6293.

\section{Publish your work in this journal}

Clinical Ophthalmology is an international, peer-reviewed journal covering all subspecialties within ophthalmology. Key topics include: Optometry; Visual science; Pharmacology and drug therapy in eye diseases; Basic Sciences; Primary and Secondary eye care; Patient Safety and Quality of Care Improvements. This journal is indexed on PubMed

Submit your manuscript here: https://www.dovepress.com/clinical-ophthalmology-journal
Central and CAS, and is the official journal of The Society of Clinical Ophthalmology (SCO). The manuscript management system is completely online and includes a very quick and fair peer-review system, which is all easy to use. Visit http://www.dovepress.com/ testimonials.php to read real quotes from published authors. 